\title{
Congress turns spotlight on US drug approval agency
}

\begin{abstract}
Washington. The US Food and Drug Administration (FDA) came under strong attack last week from both Republican and Democratic senators during hearings before the Congressional Committee on Labor and Human Resources. Most critics appeared to agree with the view of committee chairwoman Nancy Kassebaum (Republican, Kansas) that "everyone is in support of the FDA, but it could be significantly improved."
\end{abstract}

Criticisms of the FDA included charges of intimidation, claims that the agency's 'culture' is one of confrontation rather than cooperation, and that the agency - which is responsible for regulating drugs, medical devices, food and animal drugs - takes too long in approving products. But David Kessler, the FDA's commissioner said after the hearing that "some of the criticism may be of a past agency."

Senator Judd Gregg (Republican, New Hampshire) said the Congressional committee received daily complaints of unwritten rules in the agency. A letter to the agency from the House Committee on Commerce sent after a subcommittee hearing, and signed by leaders of both parties, claimed that during the hearing and in prior conversations "there appeared to be a widespread fear of retaliation by FDA personnel against witnesses, FDA employees and others who cooperate with the committee".

Barbara Mikulski (Democrat, Maryland) backed demands for reform. "There is enormous frustration with the FDA about management, enforcement and nitpicking and that must be acknowledged," she said. "We need a sense of urgency, and if we don't get it, Congress is going to roll right over you."

Other criticisms focused on complaints of the FDA's lengthy drug approval procedure. Committee member Bill Frist (Republican, Tennessee), who is a surgeon, complained of having to refuse treatment because a device available in Europe was not available in the United States. Kessler countered with an example of what happens when devices are not well regulated.

Kessler also disputed the charge that the agency is slow to approve new drugs, and pointed to reductions in average length of the review process over recent years as evidence of a general speeding-up of drug approval time. Mark Novitch, professor of health care at the George Washington University Medical Center, added that some of the reductions are a consequence of alterations in the way in which time is accounted for. But some reductions are real - and will be greater in future.

A representative of the biotechnology industry explained that the FDA's approval time was only a fraction of a drug's total development time. George Rathman, president and CEO of the ICOS corporation and a pioneer of biotechology, pointed out that the time needed to generate the data required for a new drug application is growing, now averaging almost seven years.

Asked by Senator Gregg whether he recognized the need for reform, Kessler replied that the FDA is a regulatory agency which sometimes has to say "no". Kessler added, however, that some changes were already being introduced following the release last week by the White House of a policy docu-

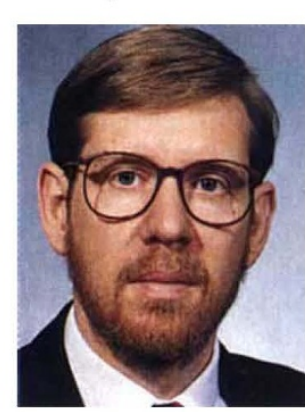
ment on FDA reform. These include relaxing the regulations on the modernization of existing manufacturing plant and allowing companies making biologics (products that are made from biological material rather Kessler: claims delays than by chemical are being reduced synthesis) to seek approval for their manufacturing processes on the basis of pilot rather than full-scale plant. The latter could save industry millions of dollars.

A spokesman for the Biotechnology Industry Organisation (BIO) said it welcomed the changes, but was disappointed that the proposals did not include outside reviews and deregulation of Phase 1 clinical trials, which examine drug action.

At present, proposals for such trials are submitted both to the FDA and to a local Institutional Review Board (IRB), made up of both scientists and lay people. The IRBs examine the design of studies, and ensure that human subjects are protected, while the FDA looks at the science involved. Industry and other observers argue that the Institutional Review Boards could also evaluate the science.

"We've had favourable reactions to this idea in conversations with people at the FDA, so we were disappointed not to see such a proposal," says Alan Goldhammer technical director of BIO. For now, proposals in the White House document requiring changes in guidelines or regulations will go ahead.

Proposals needing legislative changes must await Congress, which is likely to make some legislative changes of its own. Later this year, Kassebaum is planning to hold more hearings which will focus on specific reform proposals for the FDA.

Helen Gavaghan

\section{London gets funds to restructure its medical colleges}

London. Virginia Bottomley, the UK health secretary, has announced the government's approval of a set of new projects planned as part of the reorganization of London's hospitals around four multi-faculty colleges, each with high-class research facilities.

Bottomley was sharply criticized for appearing to ignore the opposition of groups that will see their local hospital facilities either reduced or eliminated completely as a result of the rationalization plans. But the moves have been broadly welcomed by London's biomedical research community.

The Higher Education Funding Council for England (HEFCE), for example, is to provide $£ 20$ million towards a new basic and medical science building at Imperial College. This will enable Imperial to cement a long-planned a merger with the Royal Postgraduate Medical School in Hammersmith, and with the Charing Cross and Westminster Medical School. Sir Ronald Oxburgh, the rector of the college, last week described the plans as "the opportunity of a lifetime".

The funding council has also provisionally approved a grant of $£ 14.5$ million to University College to allow it to convert the nineteenth-century Cruciform Building, the original core of University College Hospital, into a new centre for teaching and research (the Wellcome Trust has agreed to provide an extra $£ 11.5$ million towards the centre).

The Department of Health itself is providing funding for a major neurosciences and neurosurgery centre at King's College, south of the Thames, the main hub of the third cluster. The decision to place the centre at King's - earlier reviews had proposed that it be situated at Guy's Hospital, also in the same cluster - partly reflects the growing reputation of the Institute of Psychiatry at the adjacent Maudsley Hospital.

The largest lump sum, an investment of $£ 240$ million, will go towards building new facilities for St Bartholomew's and the London Hospital. These are to be combined on the site of the latter in east London to form the core of the fourth cluster.

Under a fierce attack in the House of Commons last week over some of the implications of these moves - and in particular for using a press release to announce the planned closures - Bottomley insisted that they are an attempt at "concentrating centres of expertise so that they can compete into the next century".

But her remarks came too late to dissipate the heated public opposition to many of the closures such as that of the emergency services and hospital wards at St Bartholomews' Smithfield site, where it has been active since the eleventh century (see Nature, 361, 194; 1993).

David Dickson 